\title{
Research on Physical Education Problems and Management Reform of Chinese Colleges and Universities
}

\author{
RuFeng Wang \\ Research Institute of Education Science, Wuhan University, Wuhan, Hubei, CHINA \\ School of Physical Education, South-Central University for Nationalities, Wuhan University, Wuhan, Hubei, CHINA
}

Received 7 June 2017 - Revised 16 September 2017 • Accepted 1 October 2017

\begin{abstract}
Research purpose: Chinese college students' physique condition not improved for many years, profoundly affected the national talent training quality and effect, the colleges and universities sports work caused many concerns and questions, by analyzing the problems existing in the college sports, puts forward some countermeasures for China's colleges and universities sports management reform. Research methods: the research methods of the paper are literature and questionnaire survey, which have surveyed $406 \mathrm{PE}$ teachers from 10 universities in China. The research process: the paper analyses to retrieve relevant literature, this study was carried out on the questionnaire survey information statistics, combined with the Chinese government policy document interpretation of the college sports, analyzes the realistic problems in the college sports, finally puts forward some countermeasures for the reform of sports management in colleges and universities. Results: School leaders should pay more attention to school sports; Universities should implement relevant policies of the state; Develop student development as the goal of sports work; 4 . Establish a management system of multi-subject co-participation.
\end{abstract}

Keywords: China's colleges and universities, university physical education, real problems, management reform

\section{INTRODUCTION}

Why do college students have years of physical health without reverse? Why does the country introduce regulations and regulations to strengthen college sports work, the effect is not satisfactory? Why is the "sports element" in the evaluation system of college talent? Why is there no obvious reform in college sports management system? According to the above problem, only seek answers from the national policy laws and regulations safeguard level, is clearly not enough, also should be the internal operation status of sports management system and mechanism in colleges and universities and the dilemma for answers. Constructing a set of practical and effective college sports management measures is the necessary condition for the development and management of college sports. The research methods of the paper are literature and questionnaire survey, which have surveyed 406 PE teachers from 10 universities in China. Research process: the author has been working in college sports for many years and has been thinking seriously about this issue. So the author in the thesis analyses to retrieve relevant literature, the questionnaire on the basis of the statistical information, combined with the Chinese government policy document reading of college sports, analysed the practical problems of college sports, finally puts forward some countermeasures for the reform of sports management in colleges and universities. The results of the paper are: School leaders should pay more attention to school sports; Universities should implement relevant policies of

(C) Authors. Terms and conditions of Creative Commons Attribution 4.0 International (CC BY 4.0) apply. Correspondence: RuFeng Wang, Research Institute of Education Science, Wuhan University, Wuhan 430072, Hubei, China.

$\triangle$ rufengwang2016@sina.com 


\section{Contribution of this paper to the literature}

- The author summarizes the practical problems of Chinese university sports through questionnaires.

- $\quad$ Reform of Sports Management Mode in Chinese Universities.

- The direction of the reform of sports management system in Chinese colleges and universities is the multi subject participation.

the state; Develop student development as the goal of sports work; Establish a management system of multi-subject co-participation.

\section{RESEARCH SIGNIFICANCE}

\section{The Quality Assurance Action of China's National Talent Strategy}

Youth is the future of the country and the hope of the nation. Youth is a popular nation, while a young man is strong. It is the basic and strategic work of the country to promote the better growth and development of young people. On June 23, 2016, the state council issued the national fitness plan (2016-2020), the biggest bright spot of the file is "breakthrough" of the national fitness, the national fitness as the strong support of healthy Chinese construction well-off society of national business card and signature. The service target of college sports is basically adults who have reached the age of 18 . College sports should also serve the national strategy of "healthy China".

The state of high school personnel training quality of high standards and high requirements, the specific expression is "moral, intellectual, physical and aesthetic development" of the socialist builders. The "body" should be interpreted as: physical and mental health, comprehensive sports quality is better, master more than two sports skills and participate in the general sports competitions comprehensive ability. April 13, 2017, the CPC Central Committee and State Council issued a "long-term youth development plan (2016-2025)" pointed out that to continue to enhance the nutritional level of young people and physical health, youth physical compliance rate of not less than 90\%. Hard Restrictions on Strengthening Physical Health Index in School Education. Strengthen the school sports work; improve the national sports and health curriculum standards, play a school sports assessment and evaluation system to guide the role of physical training and extracurricular exercise time to be implemented. Organize young people to participate extensively in the national fitness campaign, cultivate sports hobbies, improve physical fitness, master sports skills, develop lifelong exercise habits.

In fact, college sports still have many difficulties and problems, especially the decline of college students' physical health level has not fundamentally reversed. There are problems of insufficient students' exercise, there are problems in the teaching of physical education, there are problems of lack of supervision means, and its foothold is the reform and perfection of the college sports management system. Effective institutional arrangements are the prerequisite and guarantee of scientific management. The stability of the system can clearly guide the development direction and ensure the sharing of results. Perfect system of the system is to achieve the development of the functions of the carrier; of course, strict implementation of the system is to achieve the realistic development of shared protection.

\section{College Student's Physical Situation is Worrying; College Sports Caused Many Concerns and Doubts}

August 15, 2015, “China Youth Sports Development Report (2015)” officially released, the report shows: Chinese student's physical health problems are still prominent, overweight and obesity is serious, the incidence of myopia continues to increase, speed, strength and quality growth tends to Stagnation, endurance quality trough hovering, flexibility and quality grades for the better, poor blood pressure regulation function is more common. As one of the major Aspect, a number of physical fitness tests show that college students physical quality as high school students. 
Over the years the physical condition of college students worrying, has become a prominent problem in higher education and social concern hot issues. Chinese adolescents from primary school first grade physical education to complete the university study, at least 14 years of physical education, physical health test data in front of the physical education class seems "no credit, not to mention hard labour", criticized. Over the years, college sports experienced "competitive sports for the country glory" "quality education" happy sports "successful sports" "lifelong sports" and "health first" series of educational philosophy of change, now seems to be confused. The reason, there are many years of its "test-oriented education baton" historical issues, but also students "like sports but do not like physical education," the objective reality dilemma. However, from the system design, the college sports management system lagging behind, the reality is not perfect, to get academic proof. With the rapid development of China's modern university system and the construction of world-class universities and first-class subject goals, the innovation of university curriculum management system has become an important means to reform the current teaching management system in China; to improve the quality of university courses, but also for college sports Management system reform provides an opportunity.

\section{The Reform of College Sports Management is Imperative at Present}

On May 6, 2016, the General Office of the State Council promulgated the Opinions on Strengthening the School Physical Education to Promote the All-round Development of Students' Physical and Mental Health, aiming at "daily exercise, healthy growth and lifetime benefit" Reform and innovate the institutional mechanism, comprehensively improve the quality of physical education, improve the quality of students' personality, and earnestly play the role of sports in cultivating and practicing the socialist core values, promoting the comprehensive effect of quality education, cultivating moral and intellectual development, successor. The first one is affirmed the importance of school sports work, the second is that the school sports management system, the mechanism should be innovative reform.

Reforming the ills in the cultivation of talents in Chinese colleges and universities lies in the innovation of institutional mechanisms. Combing the school sports files, can be described as "policy stock" quite abundant, and some documents are instructive and strong binding, such as: the Third Plenary Session of the Eighteenth Central Committee of the Communist Party of China considered and adopted the "Central Committee on the comprehensive reform of a number of major issues "The basic criteria for the work of higher education in colleges and universities promulgated by the Ministry of Education on June 11, 2014 is to assess and examine the work of higher education in colleges and universities. Important basis, those who do not meet the "basic standards" requirements, the physical health of students for three consecutive years of decline in the school, "undergraduate teaching in the evaluation of colleges and universities" shall not be rated as qualified.

Graduates of college students, physical test scores of less than 50 points by finishing (that is, get the diploma and degree certificate). March 8, 2015, the Chinese State Council General Office "on the issuance of China's football reform and development of the overall program of the notice" requirements to the development of campus football as the starting point for the development of school sports. May 6, 2016, the State Council issued the "on the strengthening of school sports to promote the comprehensive development of physical and mental health of the views of students" to "every day exercise, healthy growth, life-long benefit" as the goal, reform and innovation system, comprehensively enhance the quality of physical education The To implement the solution to the problem of physical health of students as the starting point, to promote the university sports management system and the modernization of governance capacity, will become an important part of the reform of college sports.

"Sports" For the primary stage of socialism in China, its management system for many years to take the basic "top-down" model. One of the competitive sports, mass sports, sports culture, sports industry basically belong to the State Sports General Administration, school sports, including college sports belong to the Chinese Ministry of education. College sports is under the guidance of the Ministry of Education under the unified guidance of their own daily physical education teaching arrangements, the school sports culture and other issues and the physical condition of college students, college sports basic standards for supervision and inspection. Over the years, colleges and universities within the sports management mechanism and the system did not change significantly, 
conservative and inertial dependence is to a large extent bound by the college sports management system reform and innovation. Whether it is the coordinated development of national education and the need for high-quality personnel training, or the development needs of colleges and universities, college sports should not be short-board, urgent need for management system reform.

\section{RESEARCH METHODS}

The main research methods adopted in this paper are literature and questionnaire.

\section{Literature Method}

The author uses two kinds of methods, such as paper books, newspapers and periodicals, periodicals and electronic data based on Internet data, to use the method of cross-examination and reverse investigation in the literature resources to "university (university) sports" College sports "management system" and other related terms for the keyword search and analysis of the literature.

\section{Questionnaire Survey}

In this study, a questionnaire survey was conducted on 500 college physical education teachers in 10 universities in mainland China by using the survey method of random selection of colleges and universities. The way of distribution and recycling is carried out by the team members in person. A total of 461 questionnaires were collected and 406 were valid questionnaires. The data were analyzed and analyzed by EXCEL software.

\section{THE DEFINITION OF CORE CONCEPTS AND THE SUMMARY OF EXISTING RE- SEARCH RESULTS}

\section{The Definition of Core Concepts}

\section{University sports or university physical education}

“University Sports or University Physical Education", narrowly refers to the students through the daily physical education classes, to enhance physical health, improve the level of sports technology, improve nonintellectual quality of emotional and social adaptation as the main objective of the public compulsory courses. Broadly refers to the physical practice of college students as the main means, through reasonable physical education, multiple campus sports activities and scientific physical exercise process, to enhance physical fitness, improve health, improve physical quality, school sports competition and active campus sports culture for the purpose of the sports as a factor of social activities in general.

China's Ministry of Education promulgated in 2002, "the National College Physical Education Curriculum Guide" stipulates: "Physical education curriculum is the physical practice of college students as the main means, through reasonable physical education and scientific physical exercise process, to enhance physical fitness, Health and improve the quality of sports as the main goal of the public compulsory courses; is an important part of the school curriculum system; is the central part of the work of higher education. It can be seen that the college physical education curriculum is an important way to promote the harmonious development of physical and mental health, ideological and moral education, cultural science education, life and sports skills education and physical activity, which is an important way to implement quality education and cultivate all-round development talents.

\section{Management system}

Management, refers to a certain system of people, money, things, things such as planning, organization, command, coordination, control, in order to achieve the objectives of the process. System, refers to the state organs, enterprises and institutions in the institutional settings, leadership affiliation and management authority division and other aspects of the system, system, methods, forms and so on. Such as political system, economic system. 
Management system, mainly refers to the management system and management system. System specific performance in the institutional settings, the system, also known as regulations, regulations, regulations and so on.

The education system is the general term for the form, method and system of state organization and management education. Modern school management system is the modern school system of affiliation, institutional setting, management authority and responsibility and its organizational system and other muteintegrated structure system. Educational management institutions and a certain combination of norms is the education management system. School sports management system is a branch of the education system. College sports management system should also be a combination of college sports management institutions and school sports management norms.

\section{Sports management system in colleges and universities}

Sports management in Colleges and Universities, refers to the school education in accordance with the law and the laws of the law, in order to achieve the objectives of school sports management, give full play to limited human, financial, material, information and time and other factors The role of the best means and methods, the work of college sports and its internal and external factors and environmental conditions, the planning, organization, leadership, control and innovation and a series of comprehensive activities.

School sports management system, is the school sports management institutions, the division of authority, operation mode and other aspects of the system and the general term. School sports management system policy refers to the country in order to promote the smooth progress of the reform of China's school management system, the school management system reform in the management of the main body and the management of the establishment and management of norms and other aspects of the strategic and regulatory provisions Guidelines. School sports management system, the main solution is the school sports within a number of management issues or management norms, mainly related to how to regulate the school sports decision-making system, the school sports advisory system, the school sports implementation system and school sports Supervision of the relationship between the feedback system and so on.

\section{Some of the Research Literature has been Outlined}

Compared with foreign universities, China's college sports more "Chinese characteristics". As one of the educational policies and sports policy, the effective implementation of the school sports policy will be related to the full implementation of the educational policy and the expected realization of the new era of educational goals (Wang \& Zhou, 2010).

Sports management system is an important part of the national political system, including sports management institutions, the division of authority, operating mechanism and other systems and systems. The problem of sports management system is the core problem of sports development. Sports management system has a variety of attributes: institutions, systems, methods, forms, architecture, guidelines and so on. Structured, logical science of sports management system, help to promote the progress of sports, on the contrary will restrict the development of sports (Wen \& Xiong, 2013).

A country's economic system determines the sports management system, and sports management system determines the sports organization operating mechanism. Many colleges and universities sports management institutions generally by the physical education department of physical education or physical education department, the agency does not have the administrative functions, but assume the school sports administrative responsibilities and obligations, and did not establish a vice president of the leadership model (Zhang \& Qin, 2009).

China's general college sports management system is under the leadership of the school sports committee sports department system management model. In this management model, the school sports committee is mainly responsible for the development of school sports objectives, the annual sports work plan arrangements, the implementation of sports supervision and so on. The Ministry of Sports is mainly responsible for the 
implementation of school sports work, work is also very wide involved, the party secretary is responsible for party work, the director is responsible for administrative work, deputy director responsible for groups, training, competition, scientific research and student physical fitness test work, Under the Ministry of Sports has a variety of teaching and research section, responsible for the implementation of the work.

The author makes use of the theory of "institutional change" of the new institutional economics to elaborate the factors that affect the institutional changes of the college sports system, and think that organizational rigidity is an important factor influencing the changes of college sports system. The main reason is that the organization's important "members", teachers and students rarely have the opportunity to participate in the reform, the main decision-making are confined to the leaders of the office (Huang, 2017).

The problems of traditional Chinese sports are: education and teaching content of traditional methods and methods of neglect, methods of teaching, knowledge structure and ability is lagging behind. The concrete measures to implement the sports reform are: the scientific selection of teaching content, the combination of educational reform to create a good situation education, physical education teaching model of reasonable innovation, combined with the characteristics of students from the reality of education ( $\mathrm{Li}, 2013)$.

At present, China's school sports reform outstanding problem is the lack of motivation at the grassroots reform, the lack of micro-reform forces to cultivate, reform "only in the implementation of national education policy" only. It is necessary to cultivate the micro reform force to ensure that the school sports reform is driven by the policy type to the innovation of autonomy. The inevitable choice from the stage promotion to the continuity exploration is the only way to bring together the wisdom of teaching practice and push forward the reform of school sports. (Pan et al., 2017).

At present, for the school sports reform, the biggest trouble is not the curriculum, teaching reform, but the national education laws and regulations, the implementation of policy encountered a reasonable crisis. Should be through the top design of the legislative regulation, strict policy accountability, to stimulate grass-roots microreform forces and other educational governance ideas, as soon as possible to crack the current reform of school sports in China cannot, policies and regulations cannot be implemented, preaching greater than the dilemma of law and contract, For the realization of China's school sports reform "decree" to lay a benign operating mechanism (Huang et al., 2016).

The first key word in the reform and development of higher education in China is "quality". Whether it is a world-class university and a first-class discipline construction, or a comprehensive reform of higher education, or modernization of university governance system and governance ability, its meaning has pointed to the improvement of the quality of higher education (Zhang, 2015). If you stand in the perspective of improving the quality of higher education, the responsibility and mission of college sports is to improve the quality of education services for the university, for the country to cultivate a strong body of outstanding talents. So, college sports should also conform to the reform of university management system, the implementation of the new era of college sports positioning, reform the existing management system of the drawbacks.

The call for the reform of the management system in colleges and universities has been coming from the 1990 s, and the current management system is necessary in the specific historical period. However, in the 21st century, with the rapid expansion of the number and size of the school, higher education is no longer elite education, has become a mass education, the overall management system of colleges and universities lag, determines the need for reform of college sports management system. 
Table 1. Teacher's Job Burnout Survey and Statistics $(N=406)$

\begin{tabular}{ccc}
\hline Region & Number of visitors & Percentage \\
\hline Every day & 9 & $2.22 \%$ \\
\hline Most of the time & 38 & $9.36 \%$ \\
\hline Sometimes have & 186 & $45.81 \%$ \\
\hline The occasional & 133 & $32.76 \%$ \\
\hline never & 40 & $9.85 \%$ \\
\hline
\end{tabular}

\section{THE REALISTIC PROBLEMS OF PHYSICAL EDUCATION IN CHINESE UNIVERSITIES}

\section{Physical Education Teacher Supervision Measures are Missing, Strong Sense of Job Burnout}

Teachers' professionalism is the guarantee of classroom teaching quality. The physical education teachers in Chinese colleges and universities generally have a sense of self-knowledge renewal is not strong, basically followed their own in the university stage of knowledge and skills to teach students. The times in progress, science and technology in development, knowledge is updated, and physical education teachers of theoretical knowledge and teaching methods are still in place. The reason for this phenomenon is the lack of evaluation system and supervisory mechanism for the teaching level and ability of serving teachers. The existing only the Office of Academic Affairs and school supervision (the vast majority of not part of the physical education teachers) regularly from time to time on the physical education classroom to check, the key check is: whether the teacher early or early leave, there is no lesson plans, students to class How to rate. As for the physical education teacher in the physical education taught what content, classroom teaching organization is standardized, teaching means is reasonable, the students have learned the knowledge and skills, students and teachers how to evaluate each other, and so on, the supervisors are generally not concerned about.

Survey shows that physical education teachers have a sense of job burnout, only "sometimes have a sense of burnout," the teacher accounted for $45.81 \%$ of the number of investigations. Choose "no burnout" teachers only 9.85\% (As shown in Table 1).

The reason for this result is that: (1) the content of teaching and teaching methods of physical education for many years does not change; (2) the teaching of physical education teachers is a group of 18-20-year-old college students, inevitably single, monotonous; (3) physical education teachers how to teach in physical education, what to teach, the teacher a lot of freedom, there is no challenge; (4) the lack of awareness of the educational value of sports in the subconscious of physical education teachers; (5) the school did not give physical education "must be full" status, physical education teachers do not have the feeling of respect; (6) the school supervision and evaluation mechanism is missing, teachers are free.

These reasons, resulting in physical education teachers on their occupation is not too high, when there is a sense of job burnout.

\section{Students Extracurricular Physical Exercise}

Overdose, lack of exercise, mental stress, physical function degradation is the cause of sub-health of the four major killers, physical exercise is an effective way to improve the sub-health state. Extracurricular sports activities are a useful supplement to the physical education class. It is an extension of the PE teaching system in time and space. It is an organic part of the college physical education curriculum. It is also an important way to cultivate college students' physical exercise habit.

Through the investigation of the behaviour of students in their school physical education, the results showed that the choice of "very strong atmosphere" and "better atmosphere" teachers, accounting for 7.39\% of the total survey and $6.65 \%$. That is, more than half of the teachers that the school's physical exercise atmosphere is not very satisfactory (As shown in Table 2). Because college students do not love sports for many reasons, there is not 
Wang / Sports Education Management Reform Research

Table 2. Survey and analysis of extracurricular exercise atmosphere of college students $(N=406)$

\begin{tabular}{ccc}
\hline Region & Number of visitors & Percentage \\
\hline The atmosphere is very good & 30 & $7.39 \%$ \\
\hline Good atmosphere & 27 & $6.65 \%$ \\
\hline A atmosphere & 121 & $29.80 \%$ \\
\hline Atmosphere in general & 118 & $29.06 \%$ \\
\hline The lack of atmosphere & 110 & $27.09 \%$ \\
\hline
\end{tabular}

Table 3. High-level athletes in colleges and universities social competitiveness survey and analysis $(N=406)$

\begin{tabular}{ccc}
\hline Region & Number of visitors & Percentage \\
\hline Strong competitiveness & 34 & $8.37 \%$ \\
\hline Better competitiveness & 79 & $19.47 \%$ \\
\hline Competitive & 101 & $24.87 \%$ \\
\hline Lower competitiveness & 160 & $39.41 \%$ \\
\hline No competitiveness & 32 & $7.88 \%$ \\
\hline
\end{tabular}

strong sense of fitness, academic pressure, school sports resources and so on. For many reasons, the use of intelligent phones or online games on the phone to play the vast majority of leisure time. The use of intelligent phones for college students living and learning have had a tremendous impact. College students in the enjoyment of intelligent phones to bring convenient services and entertainment and leisure, but also inevitably passively accept it to bring a variety of negative effects. Many college students suffer from cell phone dependence, regardless of time without distinction of circumstances the use of intelligent phones, attention cannot be concentrated, regardless of classroom learning or participate in activities are absent-minded. As a result, college students spend far more time on intelligent phones than they spend on sports.

\section{Sports Training and Sports Competition}

Chinese colleges and universities to recruit high-level athletes have 30 years of history, this "combination of physical and educational" model is the new historical conditions to strengthen school sports, promote quality education, promote youth training for the country to cultivate and create high-quality workers And excellent sports reserve talents of a new important measure is to integrate sports, education and other resources and the implementation of the talent training strategy of the important measures, embodies the sports, education, the most fundamental training objectives, in line with the inherent requirements of personnel training.

From the perspective of personnel training, the social competitiveness of high - level athletes in colleges and universities is an unavoidable problem. In the survey of teachers' social competitiveness of high-level athletes in colleges and universities, it is considered that "highly competitive and competitive" accounts for $8.37 \%$ and $19.47 \%$ of the survey respectively. Choose the "competitive general" option of the teacher, accounting for $39.41 \%$. It can be seen that the social competitiveness of high-level athletes in colleges and universities is low (As shown in Table 3).

The state's intention to set up the high - level athletes' enrollment system in colleges and universities is to carry out the pilot experiment of "combining sports and teaching", and try to reform and innovate the competitive talents of competitive sports in our country. But this type of college students is ultimately to the community, if there is no professional knowledge of the level of culture, its employment prospects are not optimistic, to a large extent affected the sustainable development of the model. Colleges and universities in the training of students in the professional choice should be encouraged to plural, should not all "public management professional", you can also choose science, engineering, liberal arts, law, economics, management and other professional. High level athletes should not be too much to reduce the curriculum assessment criteria, otherwise the knowledge and skills of ordinary college students with a large difference between the social competitiveness is bound to low. 
Table 4. Investigation and analysis of the role of physical Fitness tests in promoting physical exercise $(\mathrm{N}=406)$

\begin{tabular}{ccc}
\hline Region & Number of visitors & Percentage \\
\hline Very useful & 23 & $5.67 \%$ \\
\hline More useful & 74 & $18.23 \%$ \\
\hline Useful & 109 & $26.85 \%$ \\
\hline Little useful & 165 & $40.64 \%$ \\
\hline No effect & 35 & $8.62 \%$ \\
\hline
\end{tabular}

\section{Test and Monitor of Physical Fitness of College Students}

The evaluation of Physical Fitness of college students is an important part of school sports work, and it is also an important part of school education evaluation system. Through the test to promote students to actively participate in physical exercise, to develop the habit of regular exercise, improve self-care ability and Physical Fitness level, has important practical significance and long-term social significance. Colleges and universities through the quality of college students to test, to assess the physical health of students, but the reality of the situation did not receive the desired results. According to the survey of physical education teachers, it can be found that only $5.67 \%$ of teachers choose "very useful"; $18.23 \%$ of teachers think "more useful"; but $40.64 \%$ and $8.62 \%$ of respondents believe that through physical testing to promote the physical exercise The role is "little effect" and "no effect" (As shown in Table 4).

The state attaches great importance to the physical health of young people, the Physical Fitness level of students as a starting point, and then promote the school sports work in an orderly manner. The original intention is good, it is a measure, but the lack of supporting the monitoring mechanism, leading to the only data theory. Many schools are concerned only with the percentage of their school students as a whole, and the data are not analyzed and summarized. The survey shows that some students think that the body side does not make sense. The school should establish and improve the student's physical health test information feedback mechanism, cannot "a measured" students do not know their physical condition, teachers do not understand the student status of the "double-blind state." May use the information platform, give full play to the early warning function, urging students to know their own situation in the case of a regular scientific daily exercise.

\section{THE MANAGEMENT MODE OF PHYSICAL EDUCATION IN CHINESE UNIVERSITIES}

It is found that the management system of college sports has followed the "vertical" management mode of the eighties and nineties in the last century. The Ministry of Education of the State Council, as the competent department of sports administration of Chinese universities, is responsible for planning and guiding the work of physical education in colleges and universities. The Department of Education is the administrative department of sports at the provincial level, which is responsible for conveying higher-level policies and regulations and guiding the sports work in colleges and universities to a certain extent. The school physical education management system, is the school sports committee is responsible for the whole school physical education, group competition and other sports work; academic office with the physical education teaching department arranges college students physical education teaching; school Communist Youth League academic department with the physical education department do sports work; Physical education teaching department is responsible for physical education, student physical fitness test, sports competition and so on.

In the organizational system, the state despite the promulgation of a large number of documents and regulations, but the colleges and universities in the implementation of the policy, always greatly reduced, and some colleges and universities basically did not implement the corresponding requirements. In the internal organizational system of colleges and universities, there is no corresponding binding documents, various departments in the absence of supervision and supervision of the work, the effect can be imagined (as shown in Figure 1). 


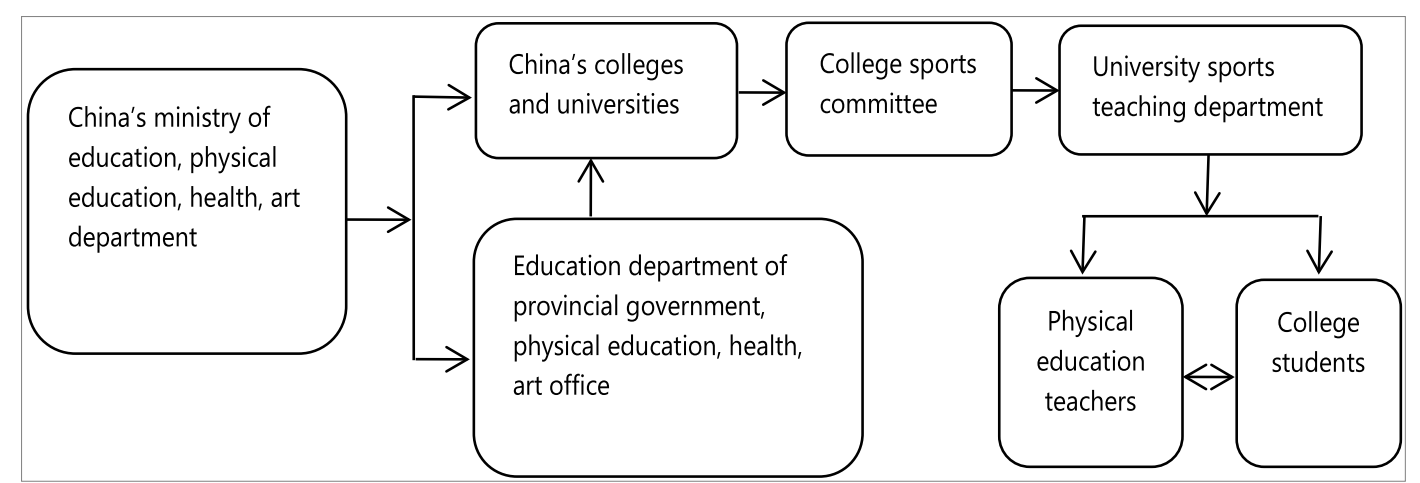

Figure 1. Structure of physical education management in Chinese universities

It is undeniable that this kind of "top-down" management system and management mode of university sports play an important role in the orderly development of college sports in certain historical periods. Over the years, colleges and universities within the sports management mechanism and the system did not change significantly, conservative thinking and management system of inertia dependence to a large extent bound by the college sports management system changes. With the gradual progress of the national governance system and the modernization of the governance capability, the gradual implementation of the reform of the management system and the higher expectation of the social work of the university have been deepened. The existing sports management system of colleges and universities has not adapted to the current development needs. Whether it is the national education undertakings and the development of high-quality personnel needs, or the development needs of colleges and universities, college sports should not be short-board, need to be based on multiple governance theory management system reform and innovation.

\section{RESEARCH CONCLUSION}

Institutional reform is a fundamental reform, unlike local reform. The reform of college physical education curriculum content, the reform of college physical education curriculum mode, the reform of college sports evaluation methods, etc., has been carried out over the years of reform and exploration, but also achieved certain results, but from the "people satisfied with the university physical education" or a large gap The reform of college physical education management system is a fundamental reform of colleges and universities, is a comprehensive, collaborative reform.

\section{School Leaders Should Pay Attention to University Physical Education}

As a university compulsory course, the Chinese Ministry of Education has attached great importance to school sports, and many regulations have been promulgated. The school level has also organized a variety of sports and cultural activities every year in accordance with the requirements of the Ministry of Education. The second year must be full of physical education points, individual schools also encourage junior, senior grade elective physical education; parents hope that children in the university to actively participate in physical exercise, lay the foundation for the development of the cause of the community that the symbol of college students is vibrant, Running, physical strength, high expectations for college sports. However, the physical health of college students for many years cannot be reversed, obesity rate, myopia, body function sub-health rate increased year by year, the state, society, schools, parents, students focus on the university physical education.

In view of the fact that the performance of the policy is weak, in the face of the fact that the college students' physical quality has been declining for a long time, neither the department nor the individual has any administrative and administrative responsibility. It seems that the relevant departments, when enjoying the public power transfer and giving, the school sports policy The diminishing administrative ethical responsibility has been "discarded" to the forgotten corner. Wang Dengfeng, director of the Department of Sports Health and Art Education of the Ministry of Education, said that it is necessary to put the students' sports work in a more 
prominent position, to carry out the physical health test and the school sports assessment, and to implement the publicity and accountability system.

\section{The School Should Truly Implement the National School Physical Education Policy}

It is undeniable that the national government level, the school level, the functional department level as well as the first-line physical education teachers, have carried out the management of all aspects of college sports. Document measures, guidelines and regulations continue to introduce, can be described as "policy stock" rich, but the government level that the school in school sports work did not fulfill the obligations. May 6, 2016, the State Council issued the "on the strengthening of school sports to promote the comprehensive development of physical and mental health of the views of students", one is sure the importance of school sports work, the second is that the school sports management system, the mechanism should to carry out innovation and reform. At the school level, although the organizational structure, the authority of the division of responsibilities are carried out on the system, but the actual management of college physical education is still the Department of Physical Education, the role of other related stakeholders did not get play. Although the community to pay attention to college sports, but the performance of third-party assessment of college sports institutions, there is no more talk about social supervision.

\section{The Student's Comprehensive Development as the Goal of Physical Education Work}

June 23, 2016, the State Council issued the "National Fitness Program (2016-2020)", the biggest highlight of the document lies in the national fitness of the "breakthrough awareness", the national fitness as a healthy China building a strong support and signature built a well-off Social country card. College sports service object is basically over 18 years of age adults; college sports should also serve the "healthy China" national strategy.

June 14, 2017, the Ministry of Education issued a "general college health education guidelines", referred to part of the health awareness of college students indifferent, to maintain and promote their own lack of health, lack of exercise, lack of sleep, irregular diet, irregular diet Unhealthy lifestyles are becoming a risk factor for students' health. Colleges and universities should help students to establish a sense of health, to master the health of knowledge and skills, the formation of a civilized, healthy lifestyle, improve their health management capacity, enhance the health of the people to maintain a sense of social responsibility to promote students' physical and mental health and comprehensive development. Teaching students' movement and health, scientific exercise principles and methods, self - monitoring of sports load (Zhang, 2017).

The state of high school personnel training quality of high standards and high requirements, the specific expression is "moral, intellectual, sports, aesthetic education in all-round development" of the socialist builders. The "sports" should be interpreted as: physical and mental health, comprehensive sports quality is better, master more than two sports skills and participate in general sports competitions comprehensive ability. In fact, college sports still have many difficulties and problems, especially the decline of college students' physical health level has not fundamentally reversed. There are problems of insufficient students' exercise, there are problems in the teaching of physical education, there are problems of lack of supervision means, and its foothold is the reform and perfection of the college sports management system. Effective institutional arrangements are the prerequisite and guarantee of scientific management. The stability of the system can clearly guide the development direction and ensure the sharing of results. Perfect system of the system is to achieve the development of the functions of the carrier; of course, strict implementation of the system is to achieve the realistic development of shared protection.

\section{The Establishment of Multi-agent to Participate in the Management System}

Over the years, the university sports management model of inertia dependence, college sports have exposed the lack of system and the responsibility of the management problems caused by unclear. June 11, 2014 promulgated and implemented the "basic standards of sports work in colleges and universities", is the general requirements of full-time ordinary college sports work, but also assessment, check the important basis for higher education in colleges and universities. The state requires the university to set up sports work institutions, equipped 


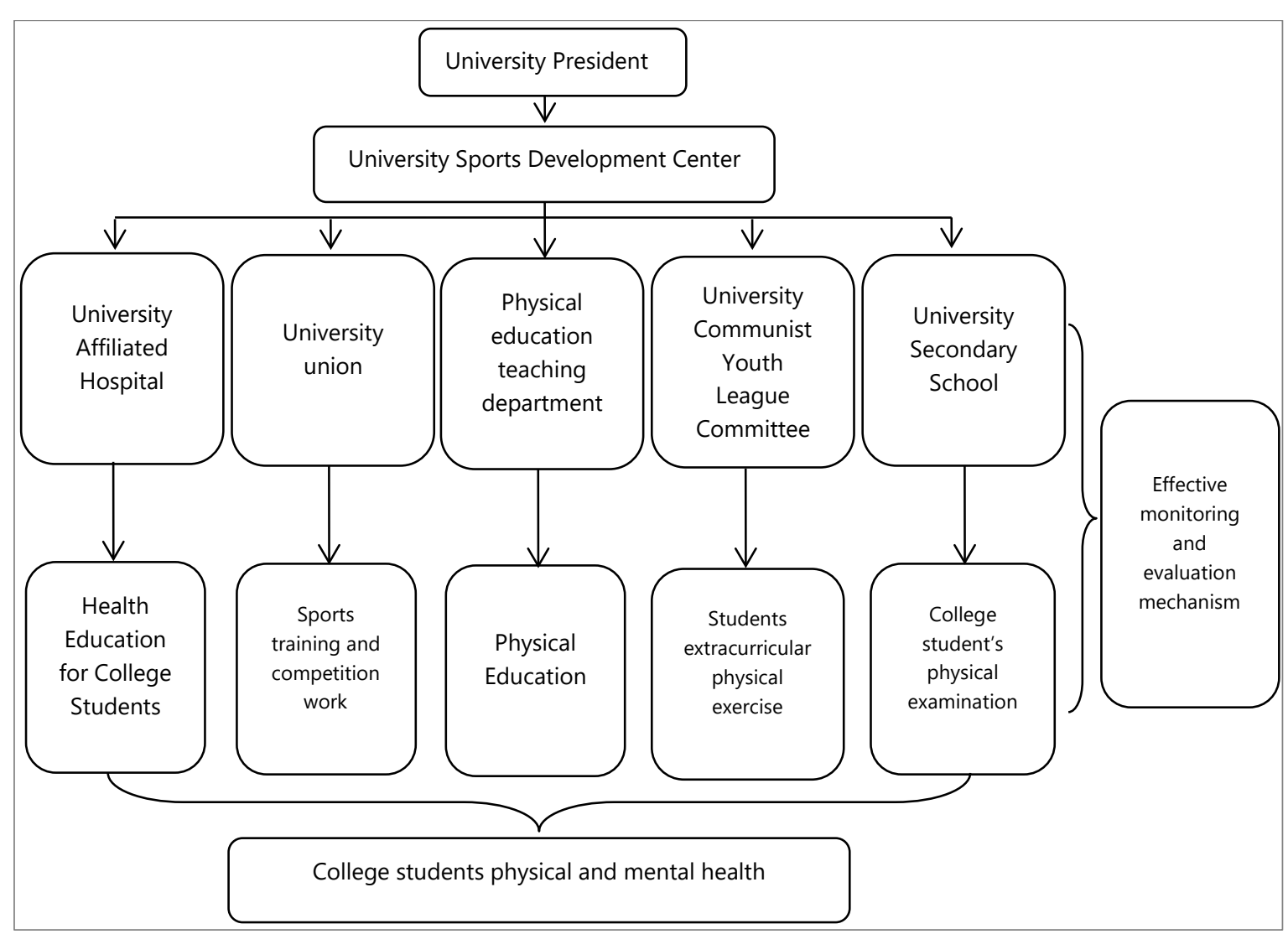

Figure 2. The Structure of Sports Management System in Colleges and Universities

with full-time cadres, teachers and staff, and give them to carry out the school sports work management functions. The relevant departments of the school actively cooperate with a reasonable division of labor, clear personnel, and the implementation of responsibility. The extracurricular sports activities into the school teaching plan improve the system (Zhang \& Peng, 2017); improve the mechanism to strengthen the protection. For all students to set up a variety of alternative, effective, effective exercise program, organize students to participate in at least three times a week extracurricular physical exercise, and effectively ensure that students one hour a day sports time. The Structure of Sports Management System in Colleges and Universities (as shown in Figure 2).

Participation is the essence of university governance, and the direct and indirect main body of university sports elements participate in school affairs governance, which is a response to the reform of institutional management in colleges and universities in the new period (He \& Ran, 2014). At present, the college sports stakeholders, usually considered to be physical education departments and students, on the grounds that: the physical education department is the responsibility of good physical education, is the necessary conditions for the existence of the department and physical education; students are educators (learn 2-3 sports skills, enhance the physical health level, through the training of social training and social quality of the will), is the necessary conditions for the existence of physical education. Those who hold this view represent the majority, which includes government education authorities and school-level policy document makers. In the deepening of the reform of the education system today, standing on the "university to cultivate what kind of person" "what is qualified talent" height, to improve the importance of college sports awareness, study the reform of sports management system of multi-party co-governance, to achieve national, School, society, individuals have the interests of the demands. Colleges and universities of the organizational units and behaviour subjects, consultation and governance, to achieve their legitimate interest's demands. The ultimate goal of the reform of college sports management system 
is to realize the maximization of the demands of pluralistic main interests, straighten out the relationship between the government and the governance order and strengthen the scientific stability of the internal management system.

\section{CONCLUDING}

The majority of young people physical and mental health, strong physique, strong will, full of vitality, is a manifestation of a strong national vitality, is a sign of social civilization and progress, is an important aspect of national comprehensive strength. Physical exercise is an effective way to improve the health of college students, and has an irreplaceable effect on the formation of young moral character, intellectual development, aesthetic accomplishment and healthy lifestyle. It is of great strategic significance to strengthen the school sports in colleges and universities, to strengthen the constitution, improve the comprehensive quality of college students, realize the modernization of education, build a strong human resources and cultivate the socialist constructors and successors of moral, intellectual and aesthetic development.

\section{REFERENCES}

He, Q., \& Ran, T. (2014). Several Basic Issues in Comprehensively Deepen the Sports Reform. Journal of Tianjin University of Sport, 29(02), 113-118. doi:10.13297/j.cnki.issn1005-0000.2014.02.008

Huang, M. R., Ding, S. Q., \& Zhang, Y. (2016). Research on the Evolution and the Future Orientation of Chinese University Sports' Value. Journal of Sports \& Science, 37(01), 87-92+29. doi:10.13598/j.issn10044590.2016.01.014

Huang, R. R. (2017). Research on the Difficulties and Approaches of University Sports. Journal of Sports E Science, 38(03), 101-107. doi:10.13598/j.issn1004-4590.2017.03.017

Li, W. M. (2003). College sports reform and development. Shanghai: Tongji university press, 86p.

Pan, L. Y., Wang, J., \& Fan, L. X. (2017). Logic Recognition and Promotion Strategies of Policy Implementation in School Physical Education - - Based on a Analytical Framework of "Notions, Interests and Institutions". China Sport Science, 37(03), 3-12. doi:10.16469/j.css.201703001

Wang, S. Y., \& Zhou, D. S. (2010). A scholastic physical education policy execution power evaluation index system. Journal of Physical Education, 17(6), 46-50. doi:10.16237/j.cnki.cn44-1404/g8.2010.06.011

Wen, H. Y., \& Xiong, W. L. (2013). Concept of sports management system. Shandong Sports Science E Technology, 35(01), 8-11. doi:10.14105/j.cnki.1009-9840.2013.01.020

Zhang, B. (2017). Research on the Development and Change of Chinese Sports Science Based on Bibliometric Analysis. Eurasia Journal of Mathematics Science and Technology Education, 13(10), 6407-6414. doi:10.12973/eurasia.2017.01073a

Zhang, B., \& Peng, P. (2017). Research on the Development of Education Resources for the Internet Plus Universities in the National Health Field. Eurasia Journal of Mathematics Science and Technology Education, 13(8), 50855093. doi:10.12973/eurasia.2017.00984a

Zhang, J. M. (2015). The Construction of the Modern University System with Chinese Characteristics: Based on The Higher Education Quality Strategy. Journal of Macro-quality Research, 3(3), 111-114. doi:10.13948/j.cnki.hgzlyj.2015.03.011

Zhang, R. L. (2008). Sports management, Second edition. Beijing: Higher education press, 112p.

\section{http://www.ejmste.com}

